\title{
PROTÓTIPO DE UM SISTEMA FERROVIÁRIO DESENVOLVIDO ATRAVÉS DA APLICAÇÃO DA METODOLOGIA DE APRENDIZAGEM BASEADA EM PROBLEMAS (PBL)
}

Celso Becker Tischer-celso.tischer@ufsm.br

Universidade Federal de Santa Maria - Campus Cachoeira do Sul

Rodovia Taufik Germano, 3013 - Passo D'Areia

96503-205 - Cachoeira do Sul-Rio Grande do Sul

Leonardo da Silveira - leonardo_dasilveira@outlook.com

Universidade Federal de Santa Maria - Campus Cachoeira do Sul

Rodovia Taufik Germano, 3013 - Passo D'Areia

96503-205 - Cachoeira do Sul-Rio Grande do Sul

Jaderson Rosa dos Santos - r.jaderson@gmail.com

Universidade Federal de Santa Maria - Campus Cachoeira do Sul

Rodovia Taufik Germano, 3013 - Passo D'Areia

96503-205 - Cachoeira do Sul-Rio Grande do Sul

Franciso Dalosto - fmdalosto@gmail.com

Universidade Federal de Santa Maria - Campus Cachoeira do Sul

Rodovia Taufik Germano, 3013 - Passo D'Areia

96503-205 - Cachoeira do Sul-Rio Grande do Sul

Valéria Rolim Marostega - arq.valeria@hotmail.com

Universidade Federal de Santa Maria - Campus Cachoeira do Sul

Rodovia Taufik Germano, 3013 - Passo D'Areia

96503-205 - Cachoeira do Sul-Rio Grande do Sul

Resumo: Este artigo apresenta a experiência do uso da metodologia de Aprendizagem Baseada em Problemas (PBL) para complementar conteúdos de disciplinas dos cursos de Engenharia de Transportes e Logística, Engenharia Elétrica, e Arquitetura e Urbanismo da Universidade Federal de Santa Maria - Campus Cachoeira do Sul. O problema proposto para aplicação da metodologia foi o desenvolvimento de um protótipo de um sistema ferroviário considerando o controle remoto de todos os equipamentos a partir de um aplicativo de celular. O projeto foi realizado em duas etapas concomitantes: o projeto elétrico ferroviário e o projeto de modelagem para a construção do protótipo. Como principais resultados desta prática, foi observada uma aprendizagem mais ativa dos conteúdos relacionados, uma vez que o trabalho em equipe promoveu o diálogo entre estudantes de áreas distintas e contribuiu para a formação profissional dos envolvidos.

Palavras-chave: Metodologia Ativa. Aprendizagem Baseada em Problemas. Sistema Ferroviário. Protótipo. 


\section{INTRODUÇÃO}

O mercado de trabalho contemporâneo tem exigido profissionais com habilidades e características que vão além de uma formação sólida. As empresas estão buscando colaboradores preparados às novas necessidades do mercado, que trabalhem de maneira efetiva, com competências relacionadas a diversas áreas do conhecimento. Entretanto, no modelo atual de ensino dos cursos de graduação, os alunos apresentam uma carência na sua formulação de competências técnicas, empreendedoras, inovadoras, pessoais e socioambientais, as quais serão de sua atribuição quando formados (CONF. NACIONAL DA INDUSTRIA, 2015).

Os principais atributos que são exigidos de um profissional no mercado de trabalho inclue $\mathrm{m}$ o comprometimento, responsabilidade, proatividade e a habilidade de trabalhar em equipe (EDUCADOR360, 2018). Percebe-se que, nos cursos de graduação, esses estímulos não são reforçados na trajetória acadêmica, pois geralmente o aluno é um agente passivo da informação e não desenvolve atividades fundamentais para seu futuro, o que resulta no despreparo deste para lidar com situações que exijam a tomada de decisão, engajamento e habilidades requeridas pela sociedade e pela indústria (SILVA, F. e PADILLO 2018).

O emprego de técnicas de aprendizagem é importante no processo de formação dos novos profissionais pois estimula a comunicação entre os alunos e o desenvolvimento de aptidões através do processo de tomada de decisão. Nesse cenário, em que se visa a formação de profissionais qualificados em suas áreas específicas e que exerçam competências distintas, insere-se a Aprendizagem Baseada em Problemas (PBL) como um método de aprendizagem inovador, no qual o professor deixa de ter um papel ativo na transferência do conhecimento e passa a ter um papel de orientador, contrapondo-se aos modelos tradicionais de ensino (SOUZA e DOURADO, 2015).

A técnica denominada Aprendizagem Baseada em Problemas é um modelo de aprendizagem dita como um recurso didático centrado no aluno, fazendo deste o principal agente responsável pelo seu aprendizado. Nessa metodologia, os alunos são expostos a projetos desafiadores com o objetivo de estimular a busca de soluções para os problemas apresentados e, assim, alcançar, de uma forma atrativa e inovadora, conhecimentos e habilidades que thes serão úteis na sua vida acadêmica e profissional (SOUZA e DOURADO, 2015; SILVA, L. et al, 2018; DIAS, Y et al, 2018).

Diante do exposto, a proposta deste trabalho é mostrar os resultados obtidos da aplicação da metodologia de Aprendizagem Baseada em Problemas, cuja proposta é o desenvolvime nto de um protótipo de um sistema ferroviário idealizado por alunos dos cursos de Engenharia de Transportes e Logística, Engenharia Elétrica, e Arquitetura e Urbanismo da Universidade Federal de Santa Maria- Campus Cachoeira do Sul (UFSM-CS). Serão expostos no artigo os procedimentos de projeto do sistema elétrico implementado, bem como os procedimentos de modelagem para a construção da maquete.

Para a realização deste trabalho, foram designadas tarefas distintas a um grupo de estudantes. Para os alunos do curso de Engenharia Elétrica, o desafio de projetar uma fonte de alimentação capaz de fornecer energia elétrica para locomotiva e para o protótipo do sistema ferroviário, além de desenvolver um aplicativo para smartphone que fosse capaz de controlar remotamente todos os equipamentos do sistema. Para os alunos do curso de Arquitetura e Urbanismo, o desafio de confeccionar uma maquete física respeitando o trajeto da locomotiva e sinalização definidos pelos alunos do curso de Engenharia de Transportes e Logística, considerando ainda fatos históricos da locomotiva e características da região Sul do Brasil. 


\section{SISTEMAS FERROVIÁRIOS}

O uso de trens movidos à tração elétrica no Brasil é praticamente exclusivo do transporte de passageiros, tais como trens urbanos, metrôs e veículos leves sobre trilhos (VLT). Trens elétricos podem possuir motores de corrente contínua (CC) ou corrente alternada (CA), independentemente de a distribuição de energia elétrica para o carro-motor ser realizada em CA ou CC (PIRES, 2006). Considerando o avanço da eletrônica de potência, a conversão CA-CC ou CC-CA é realizada, de modo eficiente, no interior dos trens.

A distribuição de energia elétrica é feita por meio de cabos aéreos ou com o uso de um terceiro trilho disposto em paralelo aos trilhos da via. Sistemas de distribuição em CA fazem uso, exclusivamente, de cabos aéreos e a conexão entre o trem e estes é feita por meio dos pantógrafos. Para os sistemas em CC, são utilizados os dois meios de distribuição citados (PIRES, 2006).

No sistema de trens metropolitanos da região de Porto Alegre - RS, a energia elétrica é proveniente de cinco subestações transformadoras/retificadoras, com potência total de 50 MVA. A distribuição de energia ao longo da via férrea é realizada em corrente contínua, na tensão de $3.000 \mathrm{~V}_{\mathrm{CC}}$, por meio de condutores aéreos (TRENSURB, 2020). Já a frota do metrô da cidade de São Paulo - SP conta com trens tracionados por motores CA e outros, por motores CC. A alimentação dos carros-motores em CC é realizada pelo terceiro trilho, em $750 \mathrm{~V}_{\mathrm{CC}}$ (METRO SP, 2020). Bondes e metrôs operam geralmente na faixa de 600 a $750 \mathrm{~V}$ em corrente contínua. Em alguns países europeus, são empregados níveis de tensão que variam de 750 a $3.000 \mathrm{~V}$ para ferrovias urbanas e suburbanas (STEIMEL, 2008).

Para o desenvolvimento do protótipo do sistema ferroviário, foi utilizado um ferrorama fabricado pela empresa Frateschi, mostrado na Figura 1, composto por uma locomotiva, vagões, trilhos, e um controlador de direção e velocidade. O deslocamento dos vagões de trem é realizado por meio de um motor $\mathrm{CC}$ contido no interior da locomotiva, cuja alimentação é proveniente dos trilhos, que contém condutores elétricos nas extremidades e fazem a distribuição de energia elétrica ao longo da linha. A energia elétrica destinada ao acioname nto do motor CC provém de uma fonte de alimentação (controlador), que fornece uma tensão ajustável de 0 a $15 \mathrm{~V}_{\mathrm{CC}}$, sendo essa a maneira mais eficiente de se alterar a velocidade de um motor CC.

Figura 1 - Ferrorama fabricado pela Frateschi. (a) Locomotiva; (b) Controlador de direção e velocidade.

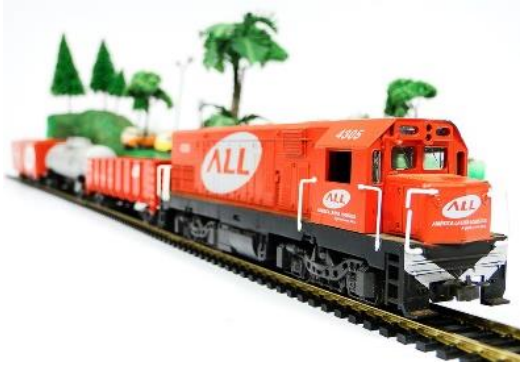

(a)

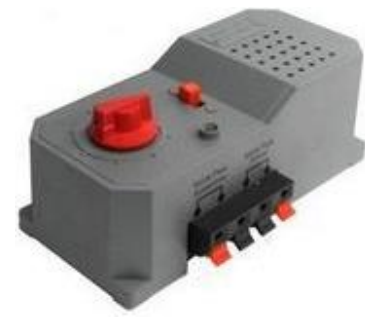

(b)

Fonte: Frateschi (2020). 
(C) COBENGE

"Os desafios para formar hoje o engenheiro do amanhã"

Nota-se que a fonte de alimentação, mostrada na Figura 1 (b), possui bornes de conexão para fornecer energia elétrica aos trilhos através de fios elétricos. Além disso, na parte superior, possui uma chave seletora, destinada a mudar a direção de deslocamento da locomotiva pela inversão de polaridade da tensão aplicada no motor $\mathrm{CC}$, e um potenciômetro, usado para modificar manualmente a velocidade na qual a locomotiva se desloca nos trilhos. Essas características impossibilitam controlar a velocidade e a direção dos vagões de trem de maneira remota, tal como encontramos em centros operacionais de trens urbanos.

\section{PROJETO DO SISTEMA ELÉTRICO}

O projeto proposto aos alunos do curso de Engenharia Elétrica para aplicação da metodologia de Aprendizagem Baseada em Problemas foi o desenvolvimento de uma fonte de alimentação capaz de fornecer energia elétrica para o sistema ferroviário considerando os seguintes requisitos:

- Tensão de saída variável de 0 a 12 V

- Controle da tensão de saída via smartphone;

- Controle da direção da locomotiva via smartphone;

- Controle dos aparelhos de mudança de via (AMV) via smartphone;

- Controle de luminosidade do protótipo via smartphone;

- Controle automático de uma barreira automotiva e sinalização semafórica.

Para alcançar os objetivos propostos, os alunos traçaram três etapas para o desenvolvimento do sistema elétrico. Na primeira etapa, investigou-se o funcionamento do ferrorama da Frateschi para estudar formas de automatização da operação do trem. Em seguida, projetou-se a fonte de alimentação de corrente contínua com os requisitos de tensão e funcionalidades solicitadas. Na terceira e última etapa, foi desenvolvido um aplicativo para smartphone para o controle remoto de todos os equipamentos do sistema ferroviário.

\subsection{Fonte de alimentação}

A fonte de alimentação desenvolvida apresenta quatro estágios de operação para a obtenção dos níveis de tensão desejáveis. A etapa inicial consiste no abaixamento da tensão CA por um transformador. Depois ocorrem as etapas de retificação, regulação e chaveamento do sinal de tensão, as quais estão detalhadas na Figura 2.

Figura 2 - Circuito esquemático da fonte de alimentação.
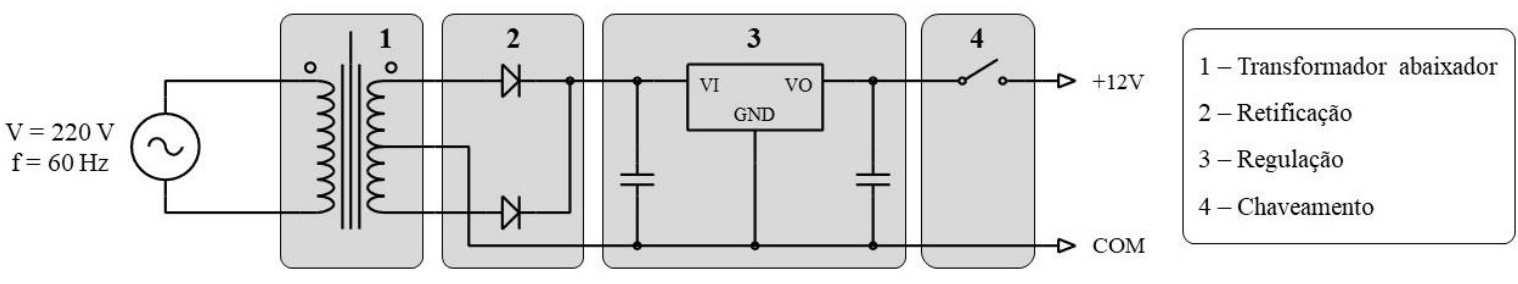

Fonte: Autores. 
No primeiro estágio, um transformador reduz a tensão de $220 \mathrm{~V}$, proveniente da rede elétrica, para $18 \mathrm{~V}$. No segundo estágio, diodos retificadores convertem a corrente alternada em contínua, sem modificar significativamente os níveis de tensão. No terceiro estágio, um filtro capacitivo é utilizado para reduzir a oscilação de tensão (ripple) nos terminais de dois reguladores de tensão, de $5 \mathrm{~V}_{\mathrm{CC}}$ e de $12 \mathrm{~V}_{\mathrm{CC}}$. Por fim, no quarto estágio, é empregada uma chave, que realiza o controle do fornecimento de energia elétrica ao sistema ferroviário.

A tensão fornecida ao motor CC da locomotiva é modificada por meio da modulação por largura de pulso (PWM), proveniente de um microcontrolador ATmega2560 e aplicada a um driver ponte $\mathrm{H}$ (TB6612FNG), responsável por variar a tensão nos trilhos de 0 a $12 \mathrm{~V}_{\mathrm{CC}}$. A direção de deslocamento dos vagões de trem é realizada pelo mesmo driver, que inverte a polaridade da tensão com um pulso digital.

A Figura 3 apresenta a fonte de alimentação implementada juntamente com o circuito de controle, que utiliza um módulo bluetooth (BT) HC-05 para realizar a comunicação serial entre o Arduino e o smartphone.

Figura 3 - Fonte de alimentação implementada.

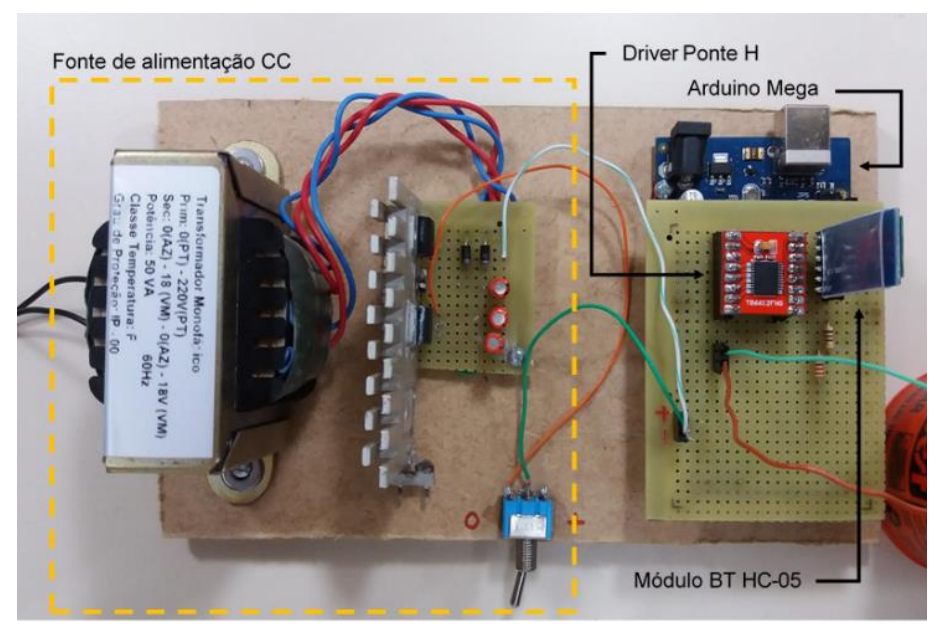

Fonte: Autores.

\subsection{Aplicativo para smartphone}

$\mathrm{O}$ aplicativo para smartphone foi desenvolvido na plataforma MIT App Inventor. Essa plataforma permite criar aplicativos complexos para Android através de blocos de programação, em um tempo menor do que os criados em ambientes de programação tradicionais, permitindo salvar e baixar o arquivo final no formato APK para ser instalado no smartphone ou tablet.

O aplicativo criado para o sistema ferroviário possui um layout composto por botões que controlam: a velocidade dos vagões de trem, a direção de deslocamento dos mesmos, os AMV para mudança de trajetória e, ainda, permite controlar a iluminação da maquete. $\mathrm{O}$ aplicativo utiliza a comunicação bluetooth do smartphone para realizar o envio das informações de controle para o Arduino. A Figura 4 (a) apresenta o layout do aplicativo desenvolvido.

O controle dos demais equipamentos previstos nos requisitos de projeto, tal como a barreira automotiva e sinalização semafórica como mostrado da Figura 4 (b), são controlados pelo Arduino Mega, utilizado devido a seu baixo custo e simplicidade de programação. 


\section{CORFNGF e III Simpósio Internacional de Educação em Engenharia 2020 da ABENGE}

"Os desafios para formar hoje o engenheiro do amanhā"

Figura 4 -Equipamentos do sistema ferroviário. (a) Aplicativo; (b) Diagrama de interligação dos equipamentos.

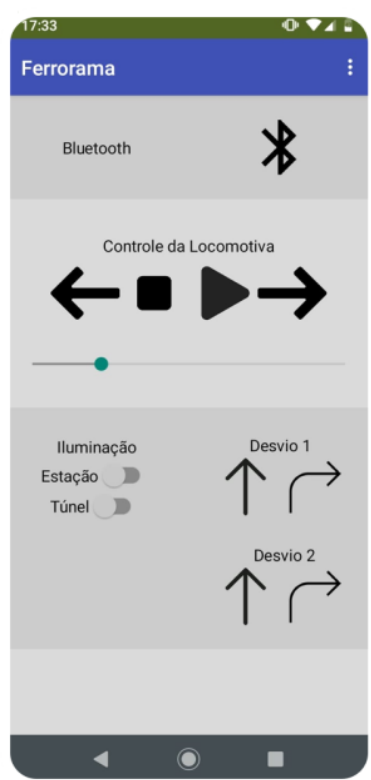

(a)

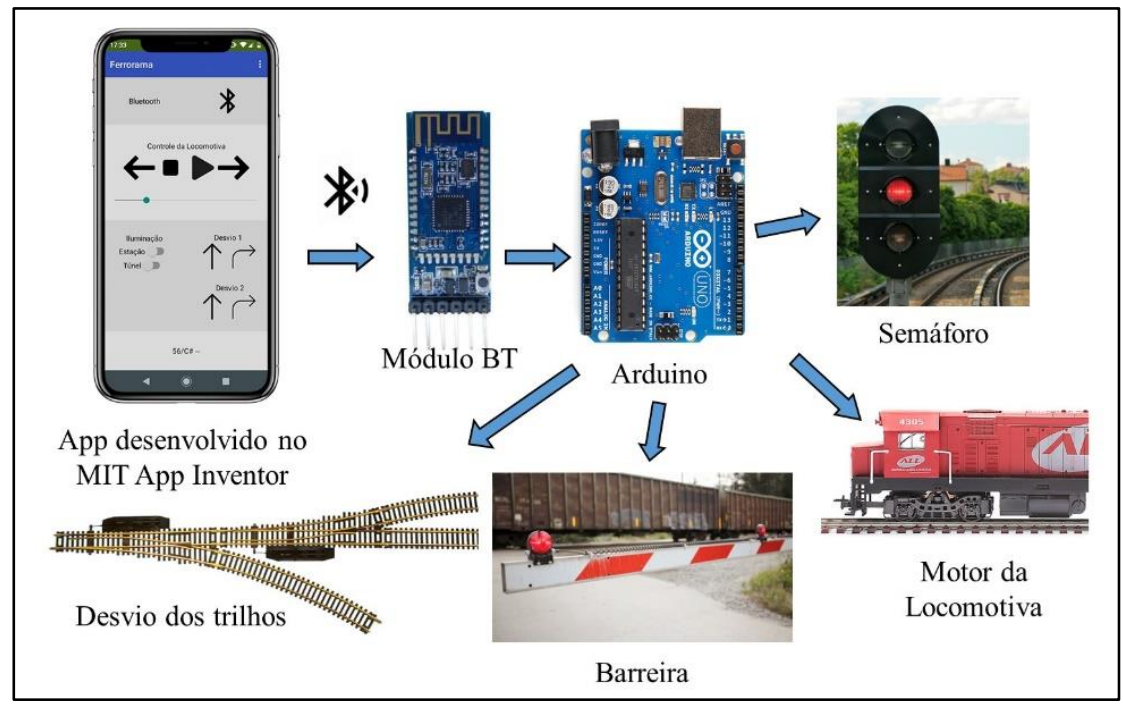

(b)

Fonte: Autores.

A Figura 5 apresenta uma foto da maquete contendo a fonte de alimentação, o sistema de controle de tensão, um semáforo e uma barreira automotiva.

Figura 5 - Foto da maquete contendo os equipamentos do sistema elétrico.

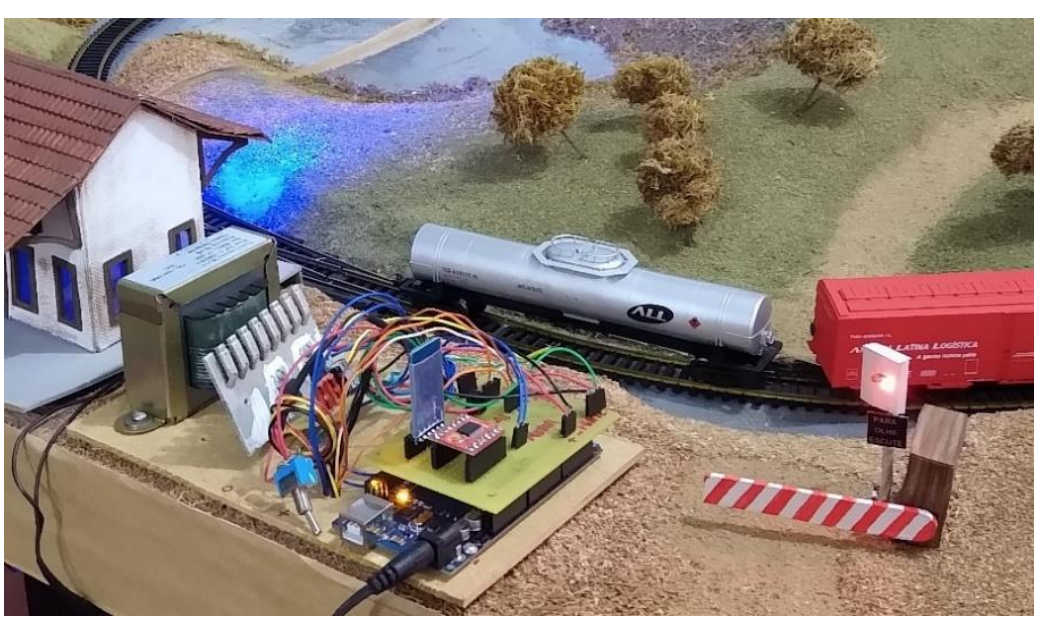

Fonte: Autores.

\section{PROJETO DE MODELAGEM}

A elaboração de modelos físicos tridimensionais nos cursos de Arquitetura e Urbanismo e Engenharias enriquece o processo de ensino e aprendizagem, pois possibilita o domínio visual e a percepção espacial da temática a ser estudada, sendo um complemento valioso para a interpretação de sistemas e tecnologias de diversos conteúdos (CONSALEZ e BERTAZZONI, 2001). É um exercício complexo de imaginação tornar palpável algo ainda inexistente, contudo proporciona a minimização de erros eventuais e a visualização de novas soluções para o projeto (MILLS, 2009). 


\section{Evento On-line}

Considerando esses aspectos e os conceitos de inserção de metodologias ativas no ensino, foi proposta aos alunos do curso de Arquitetura e Urbanismo a confecção de uma maquete do sistema ferroviário que levasse em consideração:

- O projeto geométrico estudado e traçado pelos alunos do curso de Engenharia de Transportes e Logística;

- O sistema elétrico desenvolvido pelos alunos do curso de Engenharia Elétrica;

- Escala 1/87;

- Fatos históricos da locomotiva G22U da América Latina Logística $(A L L)$ e características da região Sul do Brasil.

Inicialmente o grupo de alunos do curso de Arquitetura e Urbanismo definiu elaborar o projeto através de croquis, para testar as ideias da topografia, vegetação, edificações e composição do trajeto dos trilhos, como pode ser verificado na Figura 6 (a). Em um segundo momento, ocorreu a definição das dimensões da base para comportar os trilhos, as instalações elétricas e a logística de transporte, levando-se em consideração possibilidade de transporte da maquete.

Figura 6 -Projeto da maquete. (a) Croquis; (b) Estação de trem

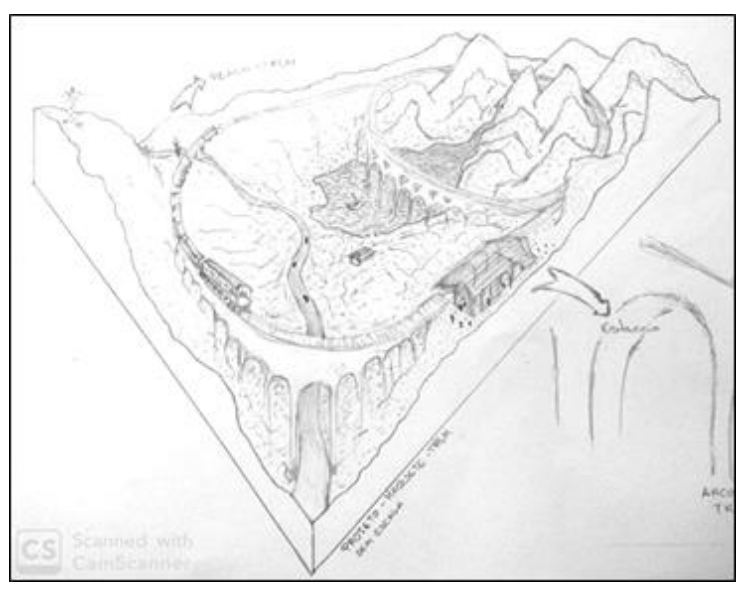

(a)

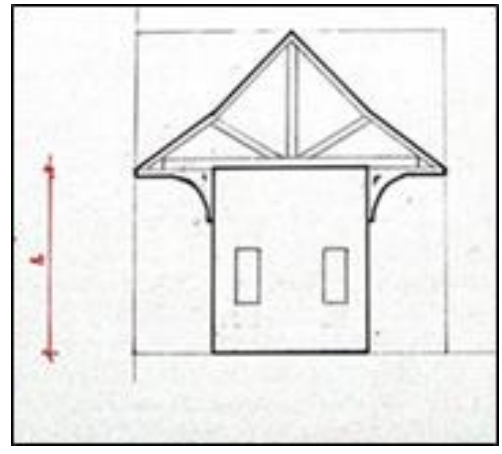

(b)

Fonte: Autores.

A paisagem considerada para a construção da maquete é característica da zona rural, com grande presença de vegetação e poucas edificações. Além disso, a história da locomotiva do ferrorama, projetada pela EMD em 1966, incentivou o projeto da principal edificação da maquete, a estação de trem, ilustrada na Figura 6 (b). Para a idealização do terreno, foram criados esboços de como seriam as curvas de nível e a topografia, já os volumes e texturas foram definidos na busca de uma perspectiva mais interessante na materialização do conjunto de massas arbóreas, morros e lago.

Para a construção da topografia do terreno, foram utilizadas placas de isopor que permitiram melhor trabalhabilidade no desenvolvimento do relevo. A textura foi criada com o emprego de serragem triturada, na maior parte da maquete, e musgo, com o objetivo de se obter uma variedade de cor e textura, a fim de se representar diferentes vegetações. O lago foi modelado com uso de tintas de artesanato, acetato e cola de silicone, de modo a chegar a um resultado que se assemelhasse à água. A confecção das edificações foi realizada com emprego papel Kraft, acetato e tintas de artesanato. 


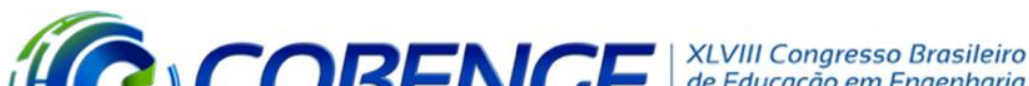 C. COBENCE $=$ $2020 \quad \begin{aligned} & \text { de Educação em Engenharia } \\ & \text { da ABENGE }\end{aligned}$}

"Os desafios para formar hoje o engenheiro do amanhã"

Por fim, para facilitar o transporte da maquete, houve a necessidade de dividi-la em duas partes, uma contendo o trajeto dos trilhos, as edificações, as barreiras automotivas e os componentes que precisavam ser conectados à fonte elétrica, e a outra, apenas complementando o trajeto dos trilhos e o ambiente idealizado. A Figura 7 apresenta o protótipo completo da via férrea inserida no ambiente.

Figura 7 - Protótipo do sistema ferroviário. (a) Estação de trem; (b) Locomotiva; (c) Sistema ferroviário

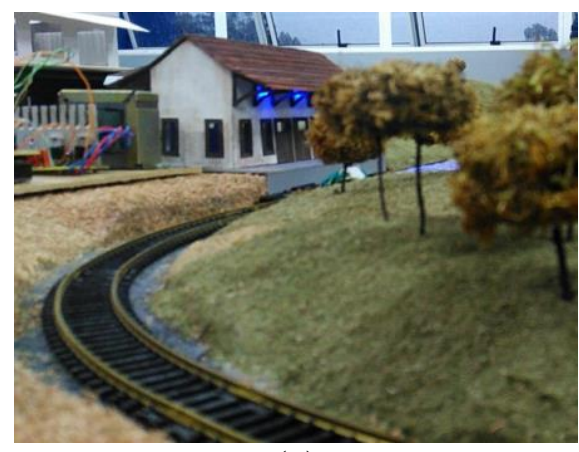

(a)

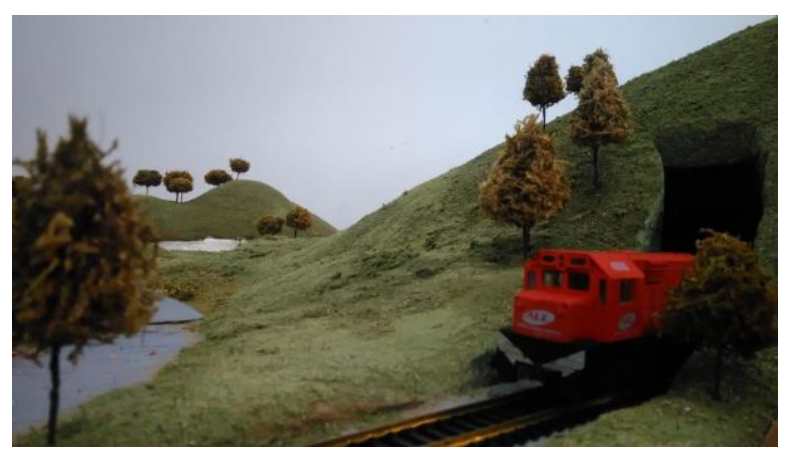

(b)

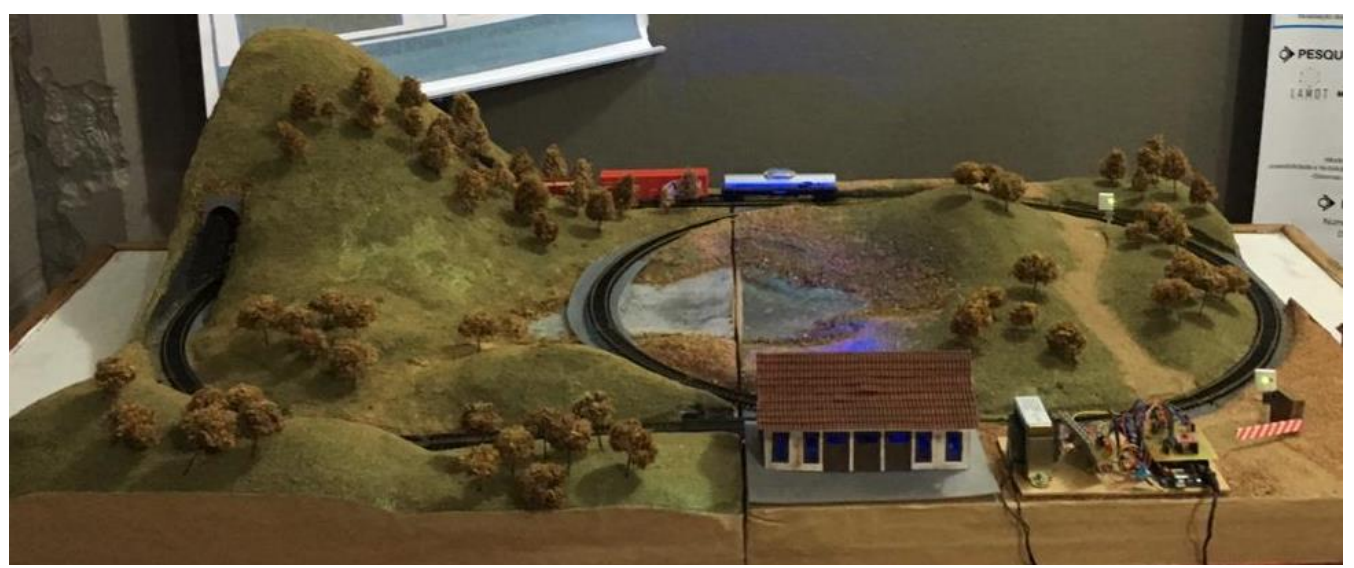

(c)

Fonte: Autores.

\section{RESULTADOS}

O protótipo do sistema ferroviário foi proposto, desenvolvido e finalizado com a colaboração de alunos e professores dos cursos de Arquitetura e Urbanismo, Engenharia Elétrica e Engenharia de Transporte e Logística ao longo do $1^{\circ}$ semestre de 2019, Figura 8. Os resultados obtidos depois do processo de execução do protótipo foram expostos e demonstrados em um evento científico promovido pela UFSM-CS chamado " 3 a Mostra de projetos da UFSM-CS" e, também, em uma palestra intitulada "Experiências nas operações de transporte ferroviário", realizada na Casa de Cultura da cidade de Cachoeira do Sul/RS. Durante as exposições, os alunos envolvidos no projeto tiveram contato com alunos de diversos semestres, ocasiões nas quais foram questionados e puderam compartilhar os conhecimentos, habilidades e experiências enriquecedoras conquistadas no período de desenvolvimento do sistema ferroviário. A demonstração e apresentação promoveram o interesse e a motivação da comunidade acadêmica, principalmente dos alunos dos semestres iniciais dos cursos do Campus. 


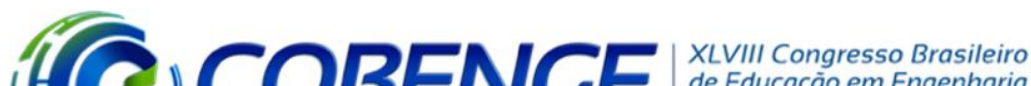 C. COBENCE $2020 \quad \begin{aligned} & \text { de Educação em Engenharia } \\ & \text { da ABENGE }\end{aligned}$}

"Os desafios para formar hoje o engenheiro do amanhã"

Atualmente o protótipo está sendo mantido nas instalações da Universidade para auxiliar nas disciplinas dos cursos da UFSM-CS.

Figura 8 - Alunos e professores envolvidos no projeto do sistema ferroviário.

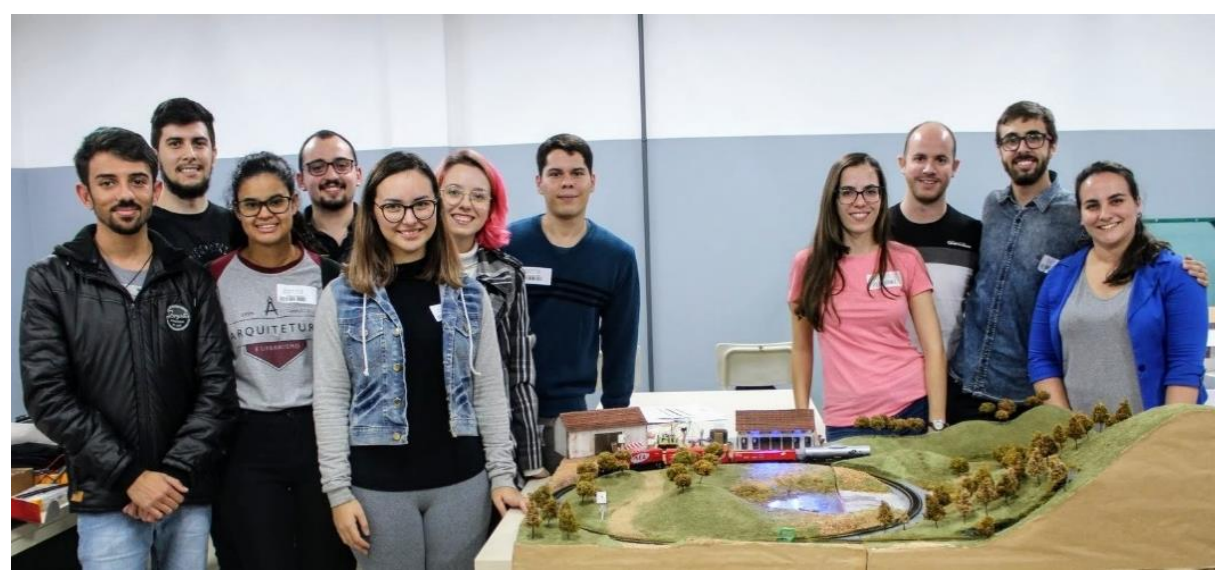

Fonte: Autores.

\section{CONSIDERAÇÕES FINAIS}

Este trabalho apresentou a aplicação da metodologia de Aprendizagem Baseada em Problemas (PBL) com o intuito de proporcionar experiências práticas a alunos dos cursos de Arquitetura e Urbanismo, Engenharia Elétrica e Engenharia de Transporte e Logística da UFSM/CS, com o desenvolvimento de um protótipo de um sistema ferroviário em escala. $\mathrm{O}$ projeto foi desenvolvido no decorrer do semestre letivo e apresentado em um evento científico promovido pela UFSM-CS.

Com a utilização do PBL como metodologia de aprendizagem ativa, os alunos desenvolveram várias habilidades de extrema importância esperadas no mercado do trabalho. Dentre as principais habilidades, estão a capacidade de trabalhar em equipe, a interação com pessoas de áreas diferentes, a iniciativa, a compreensão, a empatia, o autoconhecimento e a autoconfiança. Essas aptidões foram desenvolvidas ao longo da elaboração do projeto, desde sua concepção até a sua apresentação para a comunidade acadêmica. Por fim, ficou evidente o melhor entendimento contextual dos conteúdos abordados, o que contribui para uma aprendizagem mais ampla, completa e dinâmica.

\section{REFERÊNCIAS}

CONFEDERAÇÃO NACIONAL DA INDÚSTRIA. Fortalecimento das engenharias. Brasília: CNI. 2015.

CONSALEZ. L.; BERTAZZONI, L. Maquetes - A representação do espaço no projeto arquitetônico. São Paulo: Gustavo Gili; 2001.

DIAS, Y. E. P.; SILVA, L. H. S; NUNES, L. R.; MEDEIROS, J. S. Aprendizagem baseada em problemas na disciplina de microcontroladores: protótipo de um controle de acesso, COBENGE 2018 - XLVI Congresso Brasileiro de Educação em Engenharia, Campus UNEB, Salvador BA. 2018. 
EDUCADOR360. As 10 habilidades profissionais mais exigidas do mercado. 2018 Disponível em: https:/educador360.com/gestao/as-10-habilidades-profissionais-maisexigidas-do-mercado/. Acesso em: 03 mai. 2020.

METRO SP, POA. Metrô de São Paulo. Disponível em: http://www.metro.sp.gov.br/tecnologia/trens-frota.aspx. Acesso em: 01 mai. 2020.

MILLS, C. B. Projetando com maquetes. Porto Alegre: Bookman Editora, 2009.

PIRES, Cassiano Lobo. Simulação do sistema de tração elétrica metro-ferroviária. 2006. 424 p. Teste (Doutorado) - Departamento de Engenharia de Energia e Automação Elétricas, Escola Politécnica da Universidade de São Paulo, São Paulo. 2006.

SILVA, F. P.; PADILLO, A. R. "Project-based learning" na engenharia: uma experiência prática de aprendizado lúdico em ambiente real. Revista Ciência e Natura, Santa Maria, v.40, n.1, p 98-106, 2018.

SILVA, L. M.; TENÓRIO, E.; OLIVEIRA, V. M. Ensino de conceitos "PBL" para nível superior envolvendo sinalização ferroviária, COBENGE 2018 - XLVI Congresso Brasileiro de Educação em Engenharia, Campus UNEB, Salvador - BA. 2018.

SOUZA S. C.; DOURADO, L. Aprendizagem baseada em problemas (ABP): um método de aprendizagem inovador para o ensino educativo. Instituto Federal de Educação, Ciência e Tecnologia do RN. Holos, Rio Grande do Norte, Ano 31, Vol. 5, p 182-200, 2015.

STEIMEL, Andreas. Electric traction-motive power and energy supply: basics and practical experience. Oldenbourg Industrieverlag GmbH. Munich, 2008.

TRENSURB, POA. Metrô de Porto Alegre. Disponível em: http://www.trensurb.gov.br/home.php. Acesso em: 01 mai. 2020.

\title{
PROTOTYPE OF A RAILWAY SYSTEM DEVELOPED THROUGH THE APPLICATION OF A PROBLEM-BASED LEARNING METHODOLOGY
}

\begin{abstract}
This article presents the experience of using the Problem Based Learning (PBL) methodology to complement the contents of subjects in the Transport and Logistics Engineering, Electrical Engineering, and Architecture and Urbanism courses at the Federal University of Santa Maria (UFSM) - Campus Cachoeira do Sul. The proposed problem for applying the methodology was the development of a prototype of a railway system considering the remote control of all equipment from a smartphone application. The project was carried out in two concurrent stages: the electrical railway project and the modeling project for the construction of the prototype. The main results of this work are active learning of the related contents and teamwork, as it promoted the dialogue between students from different areas, contributing to the professional training of those involved.
\end{abstract}

Keywords: Active methodologies, problem-based learning, railway system, prototype. 